\title{
Sistem Pakar Pengenalan Ekspresi Wajah Manusia Menggunakan Metode Kohonen Self Organizing Dan Principal Componen Analysis
}

\author{
Bagus Hardiansyah $^{1}{ }^{*}$, Puteri Noraisya Primandari ${ }^{2}$ \\ 1,2Informatika, Teknik, Universitas 17 Agustus 1945 Surabaya \\ Email: ${ }^{1}$ bagushardiansyah@untag-sby.ac.id, ${ }^{2}$ puterinoraisya@untag-sby.ac.id
}

\begin{abstract}
System that can be used to recognize human facial expressions image by using Neural Network Kohonen Self Organizing Maps (K-SOM) and the method of PCA for feature extraction. Reduction results with PCA is an initialization for the clustering process on the network $(K-S O M)$. network (K-SOM) is used to divide the input pattern into groups, the image of facial expressions for grouping or clustering with methods of Artificial Neural Networks (K-SOM). (K-SOM) can group based vectors of the image of facial expressions, the network output is the group closest/similar to a given input. For facial expression recognition is done by input image size and the amount of research data. The results is $80.00 \%$ in the size of $90 \times 60$ image, in testing data 30 images of facial expressions.
\end{abstract}

Keywords: Neural Networks, Kohonen Self Organizing Map (K-SOM), Facial Expressions, Principal Component Analysis (PCA)

\begin{abstract}
Abstrak Sistem yang dapat digunakan untuk mengenali ekspresi wajah manusia menggunakan Jaringan Syaraf Tiruan Kohonen SOM sistem tersebut menggunakan metode PCA untuk ekstraksi fitur. Hasil ekstraksi fitur dengan PCA merupakan inisialisasi untuk proses klustering pada jaringan Kohonen SOM. Jaringan Kohonen SOM digunakan untuk membagi pola masukan kedalam beberapa kelompok (cluster). Kohonen SOM dapat mengelompokkan berdasarkan vektor-vektor dari citra ekspresi wajah, hasil keluaran jaringan Kohonen SOM adalah kelompok yang paling dekat atau mirip dengan masukan yang diberikan. pengenalan ekspresi wajah dilakukan dengan ukuran citra masukan dan hasilnya $80.00 \%$ didapat pada ukuran citra 90x60, dengan jumlah data pengujian 30 citra ekspresi wajah.
\end{abstract}

Kata kunci: Jaringan Syaraf Tiruan, Kohonen Self Organizing Map, Ekspresi wajah. Principal Component Analysis (PCA)

\section{Pendahuluan}

Ekspresi wajah adalah suatu perwujudan secara visual dari pernyataan, tujuan, maksud, kepribadian dan psikologi dari seorang manusia. Sistem identifikasi biometrik didasarkan pada ciri-ciri fisik dan tingkah laku atau perangai (psychology) tubuh manusia, seperti wajah, sidik jari (fingerprint), telapak tangan, mata, tanda tangan dan suara. Hal ini menjadi alternatif pilihan untuk menggantikan sistem identifikasi konvensional menggunakan password atau card yang dianggap kurang baik. Karena, terkadang kita lupa atau dicuri, sehingga dapat dibuka oleh orang lain (Majumder 2014) .

\subsection{Metode}

Jaringan Syaraf Tiruan (K-SOM) merupakan salah satu model pelatihan jaringan tanpa terawasi dan pertama kali dikenalkan oleh Prof. Teuvo Kohonen pada tahun 1990. Dalam melakukan proses pelatihan, perubahan bobot jaringan dilakukan berdasarkan parameter tertentu. Ukuran parameter yang sering digunakan adalah jarak Euclidean yang paling minimum. Selama proses pelatihan vektor contoh yang paling dekat dengan masukan akan menjadi pemenang, bobot pemenang dari vektor ini dimodifikasi terus menerus sampai didapatkan error yang paling optimal (Irawan 2008).

Struktur Kohonen SOM terdiri dua lapisan (layer) yaitu lapisan input dan lapisan output. Setiap neuron dalam lapisan input terhubung dengan setiap neuron lapisan output, dimana setiap neuron dalam lapisan 
output merepresentasikan kelas (cluster) dari input yang diberikan (Fauzet, 1994). Pada Kohonen SOM layer input (pertama) terhubung secara penuh dengan layer kompetitif (kedua) jadi setiap input unit terhubung kesemua unit output dan pada hubungan itu terdapat nilai pembobot (weight) tertentu.

\subsection{Arsitektur Jaringan K-SOM}

Arsitektur Kohonen SOM terdiri dari 1 lapisan input dan 1 lapisan output. Setiap unit pada lapisan input dihubungkan dengan semua unit dilapisan output dengan suatu bobot keterhubungan $w_{i j}$ gambar 2.3 (Irawan, 2008)

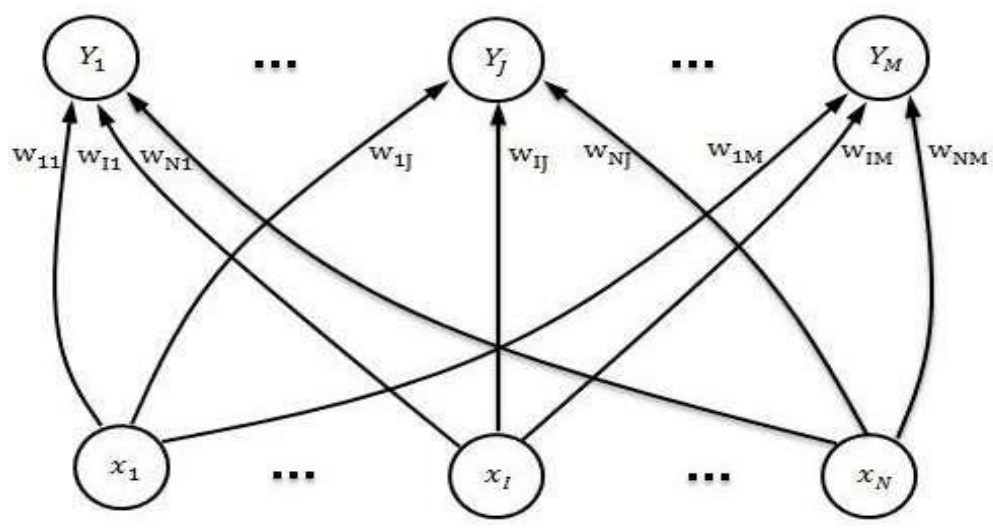

Gambar 1 Struktur Jaringan Syaraf Tiruan K-SOM

Notasi yang digunakan dalam Kohonen SOM adalah :

$X \quad$ : vektor input

$$
X=\left(x_{1}, x_{2}, \ldots, x_{j}, \ldots, x_{n}\right)
$$

$\alpha \quad$ : laju pembelajaran

$\mathrm{R} \quad$ : radius neighbourhood

$x_{i} \quad:$ neuron / node input

$\mathrm{w}_{\mathrm{ij}} \quad$ : bias pada neuron output $\mathrm{ke}-j$

$\mathrm{y}_{\mathrm{j}} \quad:$ neuron / node output $\mathrm{ke}-j$

C': : konstan

$D(j) \quad$ : jarak Eucliden atau jarak yang minimum

Berikut ini adalah tahap dalam algoritma JST Kohonen SOM [7] :

Langkah 0 : - inisialisasi bobot $\mathrm{w}_{\mathrm{ij}}$

- inputkan parameter laju pembelajaran (a)

- inputkan parameter topological neighbourhood (R)

Langkah 1 : jika syarat berhenti tidak terpenuhi (salah), kerjakan langkah 2-8

Langkah 2 : untuk setiap vektor $X\left(x_{1}, \quad i=1,2, \ldots, n\right)$ kerjakan langkah 3-5

Langkah 3 : untuk setiap indeks $j(j=1,2, \ldots, m)$ hitung jarak eucliden :

$$
D(j)=\sum_{i}\left(w_{i j}-x_{i}\right)^{2}
$$

Langkah $4 \quad$ : cari unit pemenang (indeks $j$ ), yaitu unit yang memiliki jarak $\mathrm{D}(j)$ yang terdekat (minimum).

Langkah $5 \quad$ : hitung semua nilai $w_{i j}$ (baru) dengan nilai j dari langkah 4 yaitu:

$$
w_{i j}(\text { new })=w_{i j}(\text { old })+\alpha\left[x_{i}-w_{i j}(\text { old })\right]
$$

Langkah 6 : ubah (update) nilai laju pembelajaran.

$$
\alpha(\text { baru })=0.5 \alpha(\text { lama })
$$

Langkah 7 : mereduksi radius dari fungsi tetangga pada waktu tertentu (epoch)

Langkah 8 : uji kondisi penghentian 


$$
M S E=\frac{\sum_{I=1}^{N}\left(y_{i}-\hat{y}_{i}\right)^{2}}{N}
$$

Kondisi penghentian iterasi adalah selisih antara $w_{i j}$ saat itu dengan $w_{i j}$ pada iterasi sebelumnya. Apabila semua $w_{i j}$ hanya berubah sedikit saja, berarti iterasi sudah mencapai konvergensi sehingga dapat dihentikan [16].

\subsection{Principal Component Analisis (PCA)}

$P C A$ lebih banyak digunakan untuk keperluan ekstraksi fitur citra, dimana jumlah piksel dari citra image jauh lebih besar dibandingkan dengan jumlah data sampel yang digunakan. Untuk melakukan proyeksi sampel matriks dari citra pelatihan, setiap citra pelatihan disusun dalam bentuk vektor baris (Boediono, 2009).

Proyeksi pada PCA merupakan representasi himpunan data $X$ ke dalam bentuk vektor eigen dari matrik varian-kovarian dari $X$. Vektor eigen dengan nilai eigen yang besar mempunyai peranan penting dalam proses perubahan pada nilai matrik piksel. dengan cara membuang nilai eigen yang mendekati nol tidak akan membuat kita kehilangan informasi data atau hanya kehilangan informasi yang minimum (Zaenal, 2012).

PCA perlu memasukkan data yang mempunyai sifat zero-mean pada setiap fiturnya. Sifat zeromean pada masing-masing fitur data bisa didapatkan dengan mengurangkan semua nilai dengan rataratanya. Set data $X$ dengan dimensi $M \times N$, dimana $M$ adalah baris dan $N$ kolom, akan tampak seperti berikut:

$$
X=\left[\begin{array}{cccc}
x_{11} & x_{12} & \ldots & x_{1 N} \\
x_{21} & x_{22} & \ldots & x_{2 N} \\
\vdots & \vdots & \vdots & \vdots \\
x_{M 1} & x_{M 2} & \ldots & x_{M N}
\end{array}\right]
$$

Untuk fitur ke-j, semua nilai pada kolom tersebut dikurangi dengan rata-ratanya, diformulasikan dengan

$$
x_{i j}^{\prime}=x_{i j}-\bar{x}_{j}
$$

dengan $X^{\prime}=\left[x_{i j}^{\prime}\right]$

$i=1,2, \ldots, M$

$j=1,2, \ldots, N$

$\bar{x}_{j}=$ nilai rata-rata kolom $\mathrm{ke}-j$

Selanjutnya dilakukan proses untuk mendapatkan matriks kovarian dari matriks $X^{\prime}$, yaitu $C$, dengan menggunakan formula berikut:

$$
C=\frac{1}{M} X^{\prime} \cdot X^{\prime T}
$$

$X^{\prime T}$ adalah matriks transpose dari $X^{\prime}$.

Pada matriks $C$, elemen ke-ij adalah hasil kali elemen baris matriks $X^{\prime}$ dengan kolom matriks $X^{\prime T}$. Sifat-sifat yang dimiliki oleh matriks $C$ adalah sebagai berikut:

1. $\quad C$ adalah matriks simetris bujur sangkar berukuran $M \times M$.

2. Bagian diagonal utama (dari kiri atas ke kanan bawah) adalah nilai varian masing-masing fitur sesuai dengan indeks kolomnya.

3. Bagian selain diagonal utama adalah kovarian di antara pasangan dua fitur yang berkesesuaian. Jadi, matriks $C$ merepresentasikan kovarian di antara semua pasangan yang mungkin dari fitur data set matriks $X^{\prime}$. Nilai kovarian merefleksikan noise pada fitur.

Nilai eigen dan vektor eigen dari matriks kovarian dihitung dengan menggunakan persamaan karakteristik berikut ini: 


$$
\begin{gathered}
C-\lambda I=0 \\
(C-\lambda I) v=0
\end{gathered}
$$

Dengan $C$ adalah matriks kovarian, $I$ adalah matriks Identitas, $\lambda$ adalah nilai eigen dan $v$ adalah vektor eigen.

Nilai eigen yang terbesar yang berkorespondensi terhadap nilai vektor eigen yang terbesar dipilih menjadi Principal Component. Vektor eigen yang disusun dari yang terbesar ke yang terkecil dipilih menjadi vektor fitur.

$$
\text { Vektor Fitur }=\left(e i g_{1}, e i g_{2}, e i g_{3} \ldots e i g_{n}\right)
$$

Untuk mencari Principal Component dengan $X^{\prime}$ sebagai rata-rata dihitung dengan rumus.

$$
P C=X^{\prime} \times v
$$

Langkah berikutnya melakukan transformasi data untuk menghasilkan data PCA dengan $X$ sebagai data awal.

$$
P C A \text { data }=P C^{T} \times X^{\prime T}
$$

\subsection{Normalisasi Data}

Sebelum data input diimplementasikan kedalam jaringan syaraf tiruan, terlebih dahulu melalui proses preprosessing data. normalisasi data, agar jaringan syaraf tiruan dapat mengenali data yang akan menjadi masukan bobotnya. Data akan bernilai antara 0 sampai 1 , hal ini sesuai dengan fungsi aktivasi yang akan digunakan [7] [8]

$$
f(x)=\frac{x-x_{\min }}{x_{\text {maks }}-x_{\min }}
$$

Keterangan

$f(x)=$ Data yang sudah ternormalisasi

$x \quad=$ Data yang akan dinormalisasi

$x_{\min }=$ Data terkecil dari sekumpulan data

$x_{\text {maks }}=$ Data terbesar dari sekumpulan data

\section{Tinjauan Pustaka}

\subsection{Citra Digital}

Citra merupakan nama lain dari Gambar, istilah citra biasanya digunakan dalam bidang pengolahan citra. Citra diartikan sebagai fungsi dua variabel $f(x, y), x$ dan $y$ adalah koordinat spasial dan nilai $f(x, y)$ adalah intensitas citra pada koordinat tersebut. Sedangkan citra digital adalah citra yang telah mengalami proses digitalisasi yang digunakan sebagai masukan pada proses pengolahan citra menggunakan komputer.

Citra digital dapat disajikan dalam bentuk matriks berdimensi $M x N$ dengan $M$ menyatakan baris dan $N$ menyatakan kolom. Masing-masing nilai pada matriks tersebut mewakili nilai derajat keabuan dari citra. Persamaan (14) merupakan representasi citra dalam bentuk matriks (Rafael C, 2001).

$$
f(x, y)=\left[\begin{array}{cccc}
f(0,0) & f(0,1) & \cdots & f(0, N-1) \\
f(1,0) & f(1,1) & \cdots & f(1, N-1) \\
\vdots & \vdots & \vdots & \vdots \\
f(M-1,0) & f(M-1,1) & \cdots & f(M-1, N-1)
\end{array}\right]
$$

$f(x, y)$ menunjukkan nilai keabuan.

Nilai pada baris dan kolom (pada posisi $x$ dan $y$ ) sering disebut dengan istilah piksel. Suatu piksel memiliki nilai dalam rentang tertentu, tergantung dari jenis warnanya. 


\subsection{Cropping/Pemotongan}

Cropping adalah proses pemotongan citra pada area dan koordinat tertentu. Pemotongan tersebut dilakukan dengan cara mencari piksel-piksel terluar dari setiap sisi baik sisi atas, kanan, kiri maupun bawah. Piksel-piksel terluar itulah yang akan menjadi batas pemotongan, sehingga didapatkan citra segiempat yang akan diolah dengan proses selanjutnya.

\subsection{Scalling/Penskalaan}

Scalling bertujuan untuk mengubah ukuran piksel citra asli menjadi citra yang berukuran baru, baik berukuran lebih besar atau berukuran lebih kecil. Hal ini dilakukan karena setiap citra yang diolah belum tentu mempunyai ukuran yang sama. Ukuran baru hasil Scalling didapat melalui perkalian antara ukuran citra input dengan variabel Scalling. Citra ekspresi wajah yang berukuran berbeda-beda setelah di cropping maka ukuran piksel akan direpresentasikan ke dalam matriks dengan ukuran yang sama. Scalling juga digunakan untuk memperkecil agar jumlah piksel yang akan diolah tidak terlalu banyak (Darma, 2010).

\subsection{Jaringan Syaraf Tiruan}

Jaringan syaraf tiruan dibangun berdasarkan generalisasi dari model matematika pada manusia atau syaraf biologi, didasarkan pada asumsi (Fauset 1994):

1. Pemrosesan informasi terjadi pada banyak elemen yang disebut neuron.

2. Sinyal berjalan diantara neuron yang terkoneksi jaringan.

3. Masing-masing jaringan koneksi dihubungkan dengan bobot, yang mana didalam jaringan syaraf khusus, melipat gandakan transmisi sinyal.

4. Masing-masing neuron mempergunakan fungsi aktivasi ke jaringan inputnya untuk menentukan sinyal output.

Neuron buatan sebenarnya mirip dengan sel neuron biologis. Neuron-neuron buatan tersebut bekerja dengan cara yang sama pula dengan neuron-neuron biologis.

Beberapa fungsi aktivasi yang sering dipakai adalah sebagai berikut:

a. Fungsi threshold (batas ambang) dengan threshold $\theta$

$$
f(x)= \begin{cases}1, & \text { jika } x \geq \theta \\ 0, & \text { jika } x \leq \theta\end{cases}
$$

Untuk beberapa kasus fungsi threshold yang dibuat tidak berharga 0 atau 1, tapi bernilai -1 atau 1 (sering disebut threshold bipolar). Jadi

b. Fungsi sigmoid

$$
f(x)= \begin{cases}1, & \text { jika } x \geq \theta \\ -1, & \text { jika } x \leq \theta\end{cases}
$$

$$
f(x)=\frac{1}{1+e^{-x}}
$$

Fungsi sigmoid sering dipakai karena nilai fungsinya yang terletak anatara 0 dan 1 dan dapat diturunkan dengan.

$$
f^{\prime}(x)=f(x)(1-f(x))
$$

c. Fungsi identitas

$$
f(x)=x
$$

Fungsi identitas sering dipakai apabila kita menginginkan keluaran jaringan berupa sembarang bilangan rill (bukan hanya pada range $[0,1]$ atau $[-1,1]$ (Siang, 2004).

\subsection{Pelatihan Terawasi}

Metode pelatihan pada jaringan saraf tiruan disebut terawasi jika keluaran yang diharapkan (target) telah diketahui sebelumnya. Proses pelatihan dimulai dengan menentukan nilai bobot, biasanya nilai awal bobot ditentukan secara acak atau menggunakan suatu metode tertentu. Selanjutnya dihitung keluaran menggunakan bobot yang telah diperoleh. Keluaran yang diperoleh kemudian dibandingkan 
dengan target jaringan yang telah ditetapkan sebelumnya, dengan menghitung error antara keduanya. Bila error yang dihasilkan masih cukup besar, mengindikasikan masih perlu dilakukan proses pelatihan kembali. Karena pada dasarnya tujuan dari pelatihan jaringan saraf tiruan adalah meminimalkan error pelatihan. Sehingga, pelatihan akan terus diulang hingga diperoleh error minimum yang diinginkan (Siang, 2009).

\subsection{Pelatihan Tidak Terawasi}

Pada metode pelatihan tidak terawasi tidak diperlukan target jaringan. Pada metode ini dicari vektor masukan yang memiliki kemiripan dengan vektor masukan lainnya. Bobot diperbarui hingga diperoleh vektor input yang serupa memiliki keluaran yang sama atau berada dalam kelompok yang sama. Umumnya metode pelatihan tidak terawasi digunakan dalam proses clustering (pengelompokan), pada penelitian ini Kohonen SOM termasuk pelatihan tidak terawasi. Pelatihan berhenti jika sudah tidak ada perubahan anggota kelompok yang terbentuk.

Masing-masing neuron mempunyai bagian internal, disebut aktivasi atau level aktivasi, dimana fungsinya adalah menerima input. Secara khusus, neuron mengirimkan aktivasi berupa sinyal kepada beberapa neuron yang lain. Hal penting untuk dicatat bahwa neuron dapat mengirim satu sinyal pada satu waktu, walaupun sinyal ini mengirimkan ke beberapa neuron.

Contoh : asumsi sebuah neuron yang diilustrasikan pada Gambar 2.1, menerima input dari neuron $x_{1}, x_{2}, x_{3}$. Aktivasi pada neuron ini adalah $x_{1}, x_{2}, x_{3}$ tentunya, bobot dari hubungan antara $x_{1}, x_{2}, x_{3}$ ke neuron y adalah $w_{1}, w_{2}, w_{3}$. Net input ke neuron $y$ adalah jumlah dari bobot sinyal dari neuron $x_{1}, x_{2}, x_{3}$.

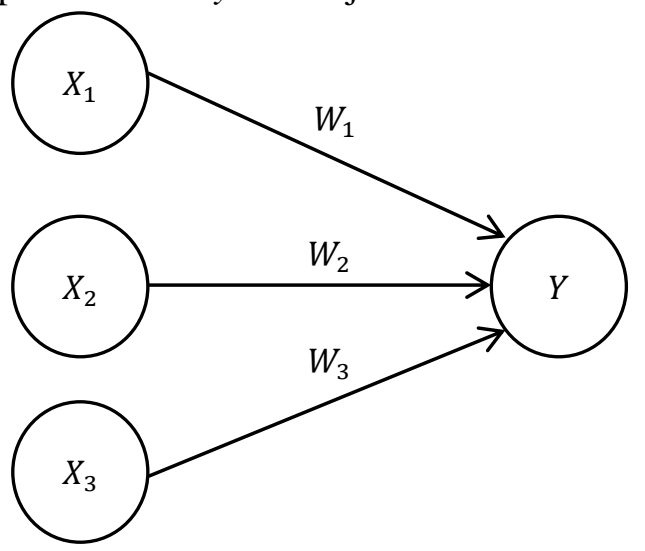

Gambar 2 Jaringan Syaraf Sederhana (Fausett, 1994)

\subsection{Kohonen Self Organizing Maps (K-SOM)}

Jaringan Syaraf Tiruan (K-SOM) merupakan salah satu model pelatihan jaringan tanpa terawasi dan pertama kali dikenalkan oleh Prof. Teuvo Kohonen pada tahun 1990. Dalam melakukan proses pelatihan, perubahan bobot jaringan dilakukan berdasarkan parameter tertentu. Ukuran parameter yang sering digunakan adalah jarak Euclidean yang paling minimum. Selama proses pelatihan vektor contoh yang paling dekat dengan masukan akan menjadi pemenang, bobot pemenang dari vektor ini dimodifikasi terus menerus sampai didapatkan error yang paling optimal (Fauzet 1994).

Struktur Kohonen SOM terdiri dua lapisan (layer) yaitu lapisan input dan lapisan output. Setiap neuron dalam lapisan input terhubung dengan setiap neuron lapisan output, dimana setiap neuron dalam lapisan output merepresentasikan kelas (cluster) dari input yang diberikan (Fauzet, 1994). Pada Kohonen SOM layer input (pertama) terhubung secara penuh dengan layer kompetitif (kedua) jadi setiap input unit terhubung kesemua unit output dan pada hubungan itu terdapat nilai pembobot (weight) tertentu. 


\section{Metode Penelitian}

\subsection{Pengambilan Data}

Dalam Penelitian ini menggunakan ekspresi wajah dari data primer yang di lakukan di Universitas 17 Agustus 1945 Surabaya menggunakan camera Fujifilm XA5. Database ini berisi 90 gambar ekpresi wajah dari 15 objek wajah, Setiap orang mempunyai 6 ekspresi yang berbeda. Terdapat 6 ekspresi yaitu netral, gembira, terkejut, sedih, mengantuk dan mata mengedip. Tabel.1 menunjukkan beberapa

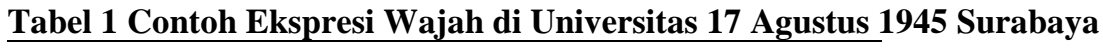

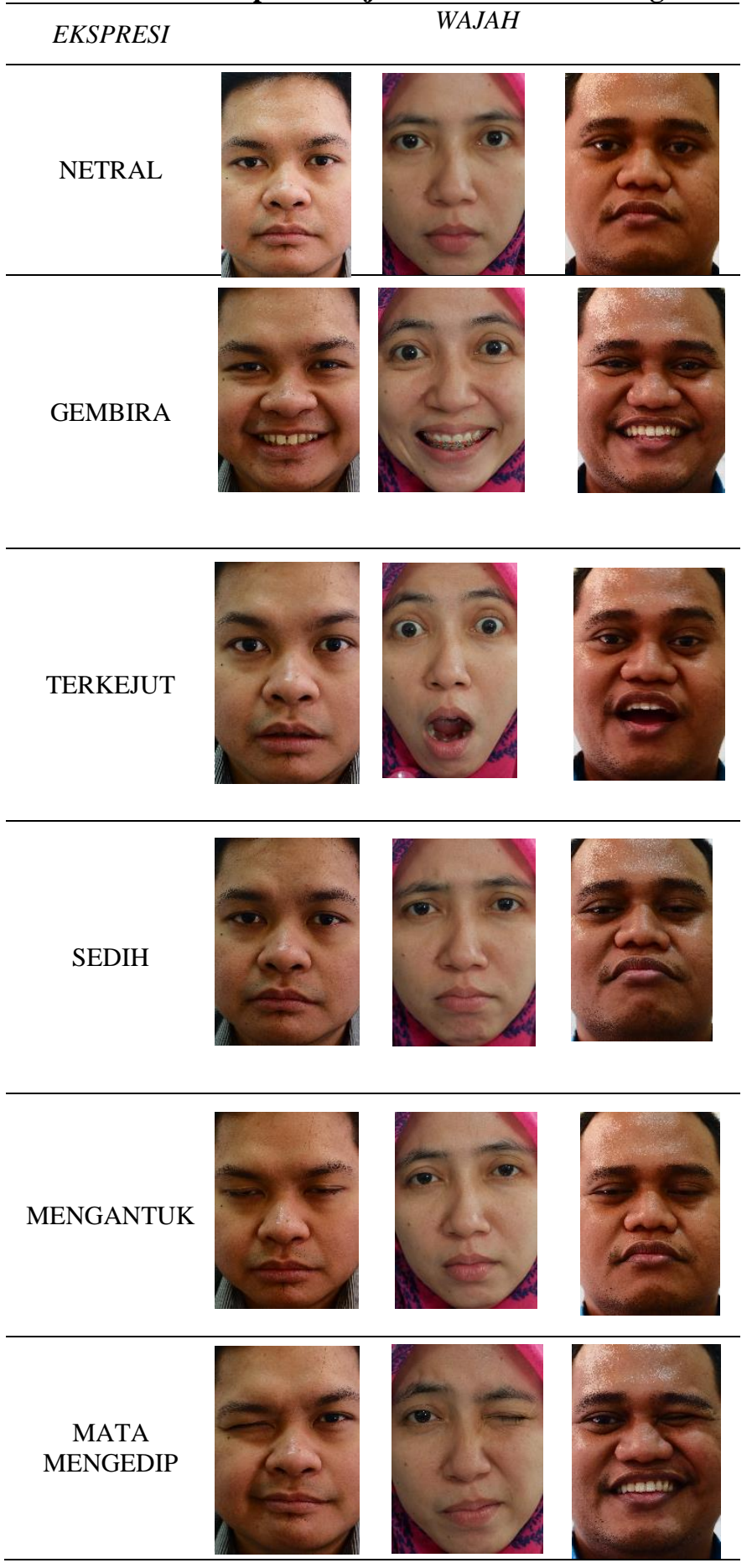




\subsection{Diagram Alir}

Diagram alir untuk menyelesaikan permasalahan yang diajukan dalam perumusan masalah ditunjukkan oleh diagram alir sebagai berikut

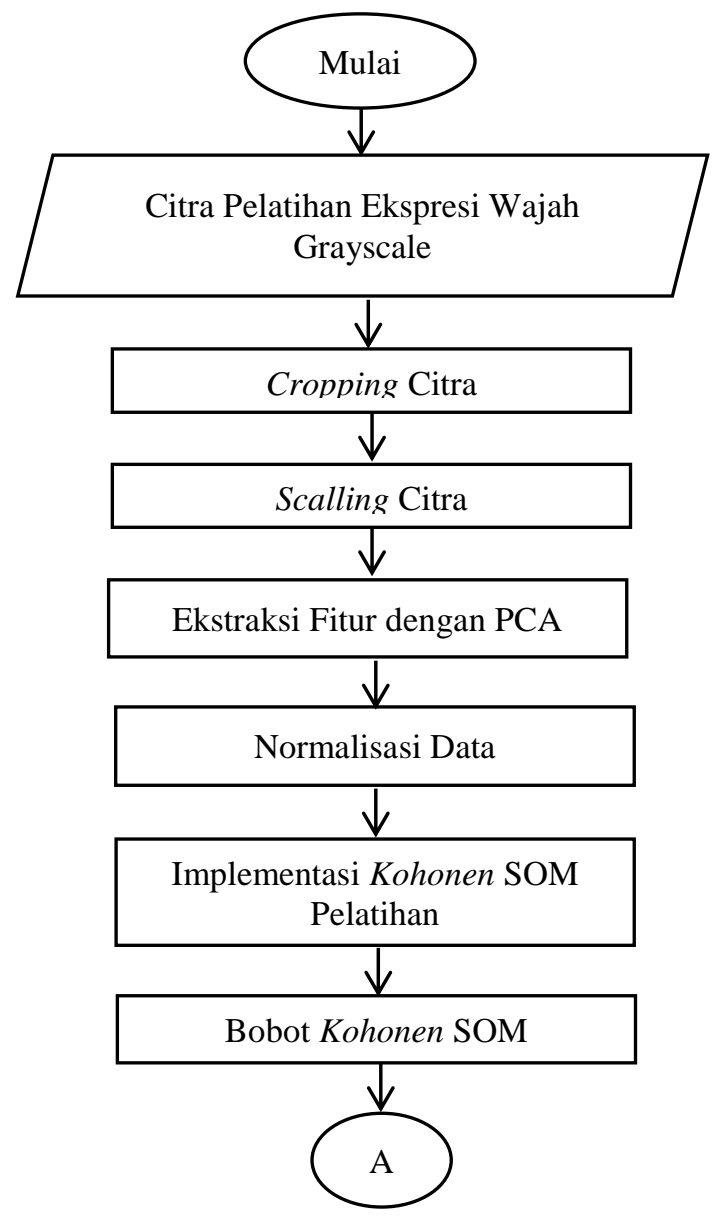

(a)

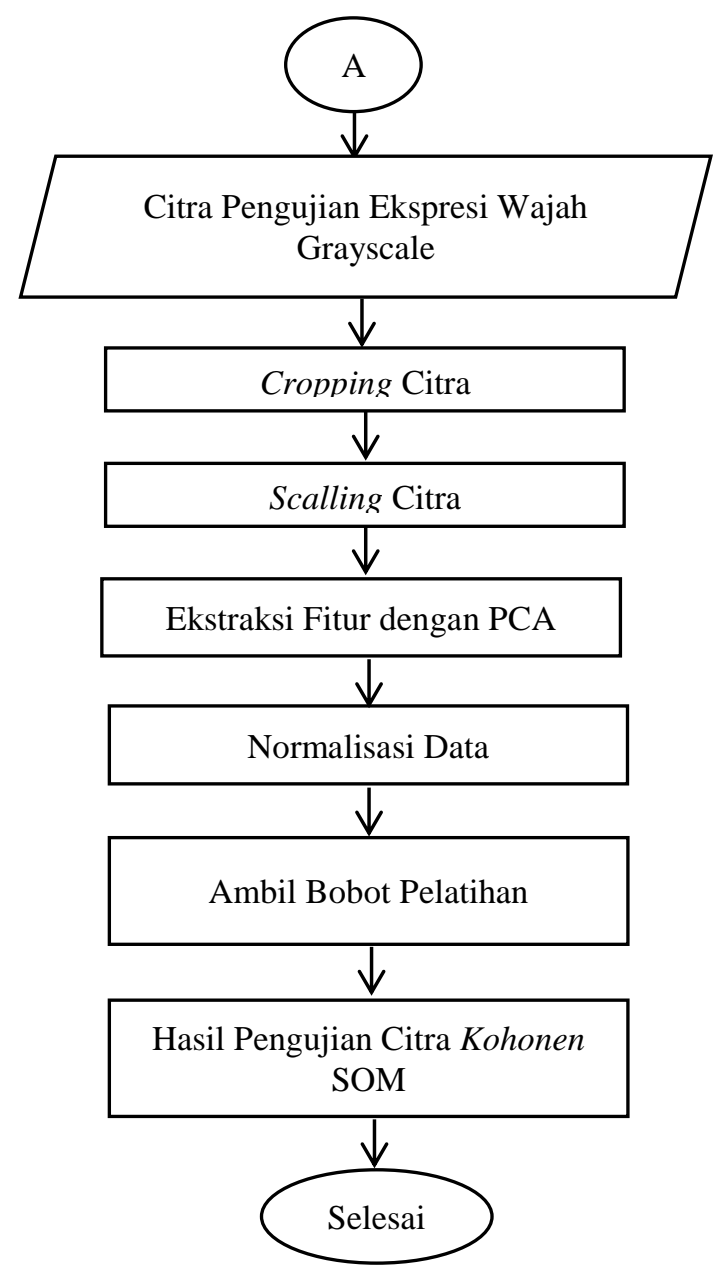

(b)

\section{Gambar 3 Diagram Alir Proses (a) Pelatihan dan (b) Pengujian}

\section{HASIL DAN PEMBAHASAN}

\subsection{Poses Pelatihan}

Dalam proses pelatihan digunakan ukuran citra ekspresi wajah 90x60, citra ekspresi wajah dengan jumlah vektor $x 1, x 2, x 3 \ldots x 5400$ dari satu citra ekspresi wajah. Data citra ekspresi yang digunakan untuk pelatihan sebanyak 60 data citra ekspresi wajah sedangkan data yang digunakan untuk pengujian sebanyak 30 data citra ekspresi wajah, jadi total ekspresi wajah yang digunakan 90 data ekspresi wajah

Sebelum dilakukan implementasi dengan program matlab, disini dilakukan proses perhitungan secara manual agar diperoleh gambaran nyata dari proses pelatihan, ukuran citra yang akan diproses yaitu 90x60 dengan jumlah 60 citra ekspresi wajah untuk pelatihan dan 30 citra ekspresi wajah untuk pengujian.

Inisialisasi : $\mathrm{R}=0, \alpha=0.8, \mathrm{a}=0.5$, vektor matrik awal yaitu ekspresi subject01 happy pada tabel 4.2 , tentukan jarak Eucliden dengan $D(j)=\sum_{i}\left(w_{i j}-x_{i}\right)^{2}$ untuk setiap indeks $\left(x_{i}, i=1,2, \ldots, n\right)$ dan $j(j=$ $1,2, \ldots, m)$ sehingga diperoleh 


\section{Iterasi ke 1}

Vektor masukkan pertama

$\mathrm{D}(1)=\|w 1-x 1\|=5.6315$

$\mathrm{D}(2)=\|w 2-x 1\|=6.1243$

$\mathrm{D}(3)=\|w 3-x 1\|=6.9211$

$\mathrm{D}(4)=\|w 4-x 1\|=6.4073$

$\mathrm{D}(5)=\|w 5-x 1\|=8.4509$

$\mathrm{D}(6)=\|w 6-x 1\|=8.3601$

$\mathrm{D}(\mathrm{j})$ minimum dapat dipilih $\mathrm{j}=1$, vektor bobot pada baris kedua dimodifikasi dengan rumus $w_{i j}($ baru $)=w_{i j}($ lama $)+\alpha\left[\left(x_{i}-w_{i j}(\right.\right.$ lama $\left.)\right]$, sehingga di peroleh bobot baru yang selanjutnya digunakan untuk vektor kedua

\section{Iterasi ke 2}

Laju pembelajaran $=0,4$ dengan bobot baru, Iterasi kedua dilakukan seperti pada iterasi sebelumnya yaitu dengan memodifikasi bobot $w$ pada baris ke $j$ sesuai dengan $D(j)$ minimum pada setiap vektor masukan. Prosesnya dilakukan berulang-ulang sampai mendapatkan bobot yang konvergen. Bobot $w$ telah konvergen pada iterasi ke-6, bobot tersebut merupakan bobot akhir yang merupakan pusat pengelompokan, jadi dalam satu citra yang berukuran 90x60 tersebut memiliki 90 vektor, dari tiap-tiap vektor masuk dalam kelompok yang sama.

Proses pengelompokan dengan ukuran 90x60 dengan jumlah 60 citra ekspresi wajah untuk pelatihan dan 30 citra ekspresi wajah untuk pengujian. Hasil pelatihan dengan jumlah 60 ekspresi wajah dapat dirangkum hasilnya sebagai berikut.

Tabel 2 Hasil Pelatihan

\begin{tabular}{ccccccccc}
\hline \multirow{2}{*}{ Cluster } & Ekspresi & 1 & 2 & 3 & 4 & 5 & 6 & jml \\
\cline { 3 - 8 } & & gembira & sedih & terkejut & mengantuk & netral & $\begin{array}{c}\text { mata } \\
\text { mengedip }\end{array}$ & per kluster \\
\hline 1 & gembira & 9 & & & 1 & & & 10 \\
\hline 2 & sedih & & 9 & & & 1 & & 10 \\
\hline 3 & terkejut & 1 & & 9 & & & 10 \\
\hline 4 & mengantuk & & & & 9 & 10 & 10 \\
\hline 5 & netral & & 1 & & 1 & & 10 \\
\hline 6 & mata & & & & & 10 & 10 \\
\hline
\end{tabular}

Hasil deskripsi dari pelatihan Kohonen SOM dengan jumlah 60 ekspresi

\subsection{Proses Pengujian}

Dari hasil pengujian dengan jumlah 30 citra ekspresi wajah dengan ukuran citra ekspresi wajah 90x60 digunakan bobot dari pelatihan dan hasilnya dapat di rangkum sebagai berikut, sedangkan pada ukuran 110x90 dan 60x50 dapat dilihat pada lampiran. 
Tabel 3 Hasil Pengujian

\begin{tabular}{|c|c|c|c|c|c|c|c|c|}
\hline \multirow[b]{2}{*}{ Cluster } & \multirow[b]{2}{*}{ Ekspresi } & 1 & 2 & 3 & 4 & 5 & 6 & jml \\
\hline & & gembira & sedih & terkejut & mengantuk & netral & $\begin{array}{c}\text { mata } \\
\text { mengedip }\end{array}$ & $\begin{array}{c}\text { per } \\
\text { kluster }\end{array}$ \\
\hline 1 & gembira & 4 & & & 1 & & & 5 \\
\hline 2 & sedih & & 4 & & & 1 & & 5 \\
\hline 3 & terkejut & 1 & & 4 & & & & 5 \\
\hline 4 & mengantuk & & & & 4 & 1 & & 5 \\
\hline 5 & netral & & 1 & & 1 & 3 & & 5 \\
\hline 6 & $\begin{array}{c}\text { mata } \\
\text { mengedip }\end{array}$ & & & & & & 5 & 5 \\
\hline Has & ersentase & & & & 80.00 & & & \\
\hline
\end{tabular}

Dari hasil kinerja berikut ini dengan ukuran 90x60, dapat diperoleh dari proses pelatihan dengan jumlah citra 60 dan pengujian dengan jumlah citra 30, maka dapat diperoleh hasil kinerja pengujian yang paling baik tingkat akurasinya dengan menggunakan alpha 0.8 yang nantinya akan di gunakan untuk proses pelatihan dan pengujian pada data citra yang lainnya.

Dari hasil eksperimen pertama didapat nilai alpha 0.8 yang terbaik tingkat akurasinya, maka jumlah data citra pelatihan dan pengujian yang akan dilakukan pada eksperimen kedua dengan nilai alpha 0.8 .

Tabel 4 Data Citra Pelatihan dan Pengujian

\begin{tabular}{|c|c|c|c|}
\hline \multirow{2}{*}{ No } & \multirow{2}{*}{$\begin{array}{c}\text { Nama } \\
\text { data }\end{array}$} & \multicolumn{2}{|c|}{ Jumlah data citra } \\
\hline & & Pelatihan & Pengujian \\
\hline 1 & kasus I & 60 & 30 \\
\hline
\end{tabular}

Ditunjukkan oleh Tabel 2 dengan ukuran citra yang berbeda ini merupakan hasil pengujian dengan ukuran 90x60 maka didapat hasil pengujian dari data citra pada kasus pengujian pada tingkat akurasi yang tinggi didapat pada ukuran citra 90x60 dengan pengujian pertama $80.00 \%$

Tabel 5 Hasil Pengujian

\begin{tabular}{ccc}
\hline \multirow{2}{*}{ No } & $\begin{array}{c}\text { Ukuran } \\
\text { citra }\end{array}$ & Kinerja pengujian $(\%)$ \\
\cline { 3 - 3 } 1 & $90 \times 60$ & Kasus I \\
\hline
\end{tabular}

Hasil deskripsi dari pengujian Kohonen SOM dengan jumlah 30 ekspresi

\section{KESIMPULAN}

Berdasarkan hasil dan pembahasan dapat diambil kesimpulan sebagai berikut:

1. Penelitian ini telah berhasil melakukan pengenalan ekspresi wajah menggunakan Jaringan Syaraf Tiruan Kohonen Self Organizing Maps (K-SOM).

2. Berdasarkan eksperimen yang telah dilakukan, maka diperoleh nilai alpha 0.8 dengan tingkat akurasi yang tinggi dan jumlah data pengujian terbaik 30 citra ekspresi wajah dengan kinerja $80.00 \%$.

3. Kesalahan dalam mengenali citra ekspresi wajah disebabkan ada beberapa noise sehingga hasil dari pengenalan citra ekspresi wajah tidak maksimal. 


\section{Referensi}

Boediono, S. (2009). Pemanfaatan Jaringan Syaraf Tiruan Kohonen Self Organizing Maps Untuk Pengenalan Wajah. Tugas Akhir Jurusan Matematika ITS Surabaya

Fausett, L. (1994). Fundamentals of Neoral Networks. Architectures, Algorithms and Aplications. Prentices-Hall, New Jersey: USA.

Gonzales, R. C. dan Wood, R. E. (2001), Digital Image Processing. Edition, Prentice-Hall.inc.

Hardiansyah, Bagus. Pengenalan Ekspresi Wajah Menggunakan Jaringan Syaraf Tiruan Kohonen Self Organizing Maps (K-SOM). (2015). Seminar Nasional Matematika dan Pendidikan Matematika Unesa Surabaya. Surabaya. Unesa University Press. $51-57$.

Irawan, M. I. (2008). Exploratory Data Analysis dengan JST - Kohonen SOM: Struktur Tingkat Kesejahteraan Daerah Tk II se Jawa Timur. Institut Tehnologi Sepuluh Nopember.

Kurdthongmee, W. (2008). Color Classification of Rubberwood Boards for Fingerjoint Manufacturing Using a SOM Neural Network and Image Processing. Computer and Electronics in Agriculture 64, 85-92.

Leksmi P. dan Sasikumar M. (2009). Analysis of Facial Expression using Gabor and SVM. International Journal of Recent Trends in Engineering 2 (1).

Li, J., Hao, W., dan Zhang, X. (2015). Learning Kernel Subspace for Face Recognition. Neurocomputing (151), 1187-1197.

Majumder A., Behera L. dan Subramanian V. K. (2014). Emotion Recognition From Geometrical Facial Features Using Self-Organizing Maps. Pattern Recognition (47) 1282-1293.

Purnomo, M. H. dan Muntasa A. (2010). Konsep Pengolahan Citra Digital dan Ekstraksi Fitur. Graha Ilmu, Edisi Pertama.

Reddy K. R. L., Babu G.R., dan Kishore L. (2010). Face Recognition on Eigen Feature of Multy Scale Face Components and an Artificial Neural Network. Procedia Computer Science (2) 62-74.

Siang, J. J. (2005). Jaringan Syaraf Tiruan dan Pemrogramannya Menggunakan Matlab. ANDI Yogyakarta.

Sun T. dan Tien F. (2008). Using backpropagation neural network for face recognition with 2D + 3D hybrid information. Expert System with Application (35) 361-372.

Sutarno. (2010). Identifikasi Ekspresi Wajah Menggunakan Alihragam Gelombang Singkat (Wavelet) dan Jaringan Syaraf Tiruan Learning Vector Quantization (LVQ). Seminar nasional Informatika UPN Veteran Yogyakarta, 87-94

Wasista, S., Bayu, B. S., dan Putra, S. A. (2011). Sistem Pengenalan Wajah Pada Mesin Absensi Mahasiswa Menggunakan Metode PCA dan DTW. Industrial Electronics Seminar, 224-229.

Yusob, B., Shamsuddin, S. M., dan Hamed, H. N. A. (2013). Spiking Self-Organizing Maps for Classification Problem. Procedia Technologi 11, 57-64.

Zaenal, A. (2012). Rancang Bangun Sistem Pengenalan Ekspresi Wajah Menggunakan Fisherface dan Jaringan Syaraf Tiruan Backpropagation. Jurnal FMIPA UNNES 35 (2), 194-203. 
Halaman ini sengaja dikosongkan 